\title{
Adrenal Gland Pheochromocytoma and Sympathetic Paraganglioma by AJCC v8 Stage
}

National Cancer Institute

\section{Source}

National Cancer Institute. Adrenal Gland Pheochromocytoma and Sympathetic

Paraganglioma by A/CC v8 Stage. NCI Thesaurus. Code C141128.

A term that refers to the staging of adrenal gland pheochromocytoma and sympathetic paraganglioma, following the rules of the TNM AJCC v8 classification system.

Parasympathetic paragangliomas are not staged because they are largely benign. This staging system does not apply to neuroendocrine tumors of the pancreas (are staged according to the classification for neuroendocrine tumors of the pancreas) and carotid body tumors (not staged). (from AJCC 8th Ed.) 